\title{
Study on safety and compatibility of controllability and stability test and square for large bus
}

\author{
LI Wen-liang ${ }^{1, ~ a ~}$, ZHOU Wei ${ }^{1, b}$, ZHAO Yu-kun ${ }^{1, c}$ and ZHAO Lei ${ }^{1, d}$ \\ ${ }^{1}$ Research Institute of Highway Ministry of Transport, Beijing 100088, China \\ awl.li@rioh.cn, ㅎw.zhou@rioh.cn, cyk.zhao@riho.cn, I.zhao@rioh.cn
}

Keywords: large bus, controllability and stability, test square, safety, compatibility

Abstract. The simulation model of the large bus was verified by real vehicle test, and simulation test of GB/T6323-2014 was carried out, and the safety and compatibility of the test and square were analyzed. The results show that the controllability and stability test can be completed in the square, but part of the test can only in the diagonal region. The lateral acceleration should be controlled within $0.6 \mathrm{~g}$ for safety.

\section{Introduction}

At present, the test method has been developed for controllability and stability at home and abroad. From the beginning of the last century, the United States Automobile Engineering Association (SAE)[1], the Japanese Automobile Industry Association (JASO)[2-7] and the international standard organization ISO[8-16], have been developed and implemented a series of standards for vehicle controllability and stability. China from its national conditions, with reference to foreign standards, from the last century 80's began to develop and improve the relevant test standards [17-21]. At present, there are many test methods for controllability and stability, mainly including step test, angle pulse test, sine input test, returnability test, pylon course slalom test, lane change test and steady circle test.

GB/T6323-2014 is the main basis for vehicle controllability and stability test, and the following simulation test is based on the standard. A square of $330 \mathrm{~m} * 330 \mathrm{~m}$ has been built, safety and compatibility of controllability and stability test and the square for large bus is studied.

\section{Establishment and validation for simulation model}

A simulation model was established with two axis (Tour Bus 5.5T/10T). The model parameters are shown in Table 1.

Table 1. Parameters of simulation model

\begin{tabular}{cc}
\hline Physical meaning & Value \\
\hline Length*Width*Height $[\mathrm{mm}]$ & $9380 * 2500 * 3500$ \\
Wheelbase $L[\mathrm{~mm}]$ & 4500 \\
Tread $B[\mathrm{~mm}]$ & $2020 / 1800$ \\
Sprung mass $M / \mathrm{kg}$ & 8120 \\
Distance from centroid to front axle $L_{l}[\mathrm{~mm}]$ & 3238.2 \\
Centroid height $h /[\mathrm{mm}]$ & 1200 \\
Rotary inertia around $X$ axis $I_{x x}\left[\mathrm{~kg} / \mathrm{m}^{2}\right]$ & 9825.2 \\
Rotary inertia around $Y$ axis $I_{y y}\left[\mathrm{~kg} / \mathrm{m}^{2}\right]$ & 39300.8 \\
Rotary inertia around $Z$ axis $I_{z z}\left[\mathrm{~kg} / \mathrm{m}^{2}\right]$ & 39300.8 \\
\hline
\end{tabular}

As shown in Table 2, the simulation test was carried out and compared with the real vehicle test. The steady-state steering test was carried out at the speed of $30 \mathrm{~km} / \mathrm{h}$ and turning radius of $20 \mathrm{~m}$.

From Table 2 we can see that the relative error between roll angle and lateral acceleration is not more than $1 \%$, which proves the scientific and accuracy of the model. The speed control of real vehicle test is not stable, which influences on the relative error. 
Table 2. Comparison of simulation with real vehicle test

\begin{tabular}{llll}
\hline Steady-state steering & Real vehicle & Simulation & Relative error \\
\hline Roll angel $\delta[\operatorname{deg}]$ & 2.150 & 2.144 & $0.28 \%$ \\
Lateral acceleration $a_{y}[g]$ & 0.353 & 0.350 & $0.85 \%$ \\
\hline
\end{tabular}

\section{Simulation and analysis}

Steady static circular test of closed loop. The vehicle accelerates from 0 to $100 \mathrm{~km} / \mathrm{h}$ with $50 \mathrm{~s}$. The radius is $30 \mathrm{~m}$. At the time of $26 \mathrm{~s}$, vehicle speed reaches $50 \mathrm{~km} / \mathrm{h}$, and left rear tire is off the ground with the lateral acceleration of $0.6 \mathrm{~g}$, as shown in Fig. 1 . The velocity of real vehicle test should not be higher than $50 \mathrm{~km} / \mathrm{h}$, and the lateral acceleration should not be beyond $0.6 \mathrm{~g}$. As shown in Fig. 2, the test field should not be less than $65 \mathrm{~m} * 65 \mathrm{~m}$.

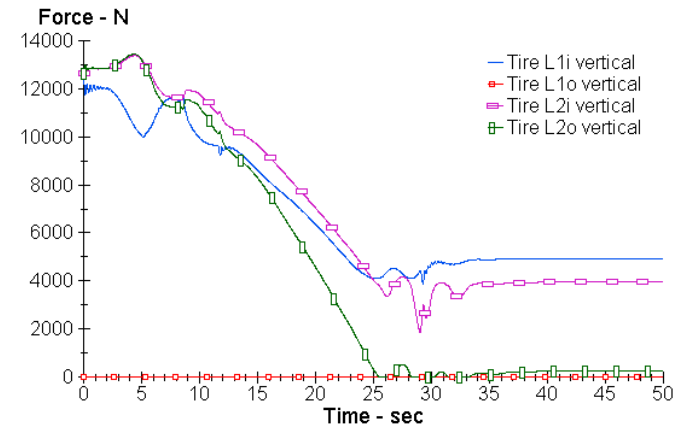

Fig. 1 Vertical forces of left tires of steady static circular test of closed loop



Fig. 2 Center of tire contact of steady static circular test of closed loop

Steady static circular test of open loop. The vehicle accelerates from 0 to $90 \mathrm{~km} / \mathrm{h}$ with $100 \mathrm{~s}$. The radius is $30 \mathrm{~m}$, and steering wheel angle is $218.2^{\circ}$. At the time of $61 \mathrm{~s}$, vehicle speed reaches $55 \mathrm{~km} / \mathrm{h}$, and left rear tire is off the ground, as shown in figure 1 . The velocity of real vehicle test should not be higher than $55 \mathrm{~km} / \mathrm{h}$. As shown in Fig. 3, the test field should not be less than $75 \mathrm{~m} * 75 \mathrm{~m}$.

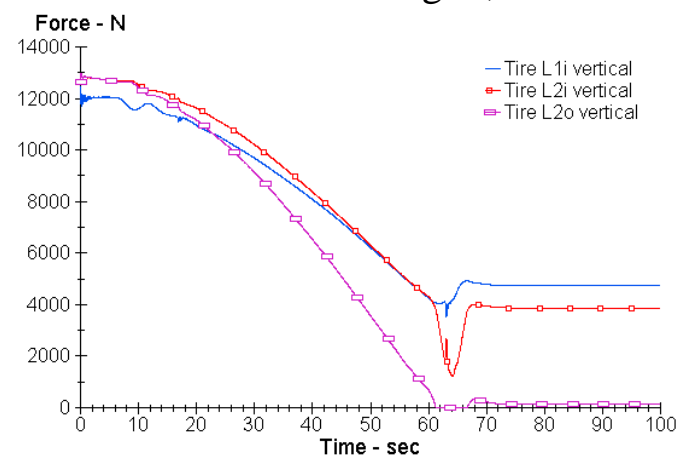

Fig. 3 Vertical forces of left tires of steady static circular test of open loop

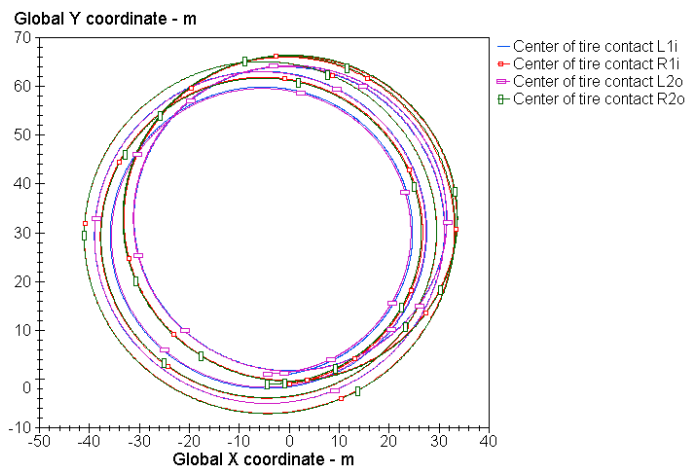

Fig.4 Center of tire contact of steady static circular test of open loop

Pylon course slalom test. The speed is set to $80 \mathrm{~km} / \mathrm{h}$. As shown in Fig. 5, both sides of tire vertical forces were not zero, indicating no rollover risk. As shown in Fig. 6, the test field should not less than $350 \mathrm{~m} * 4 \mathrm{~m}$ without the accelerating and braking distance, only the square diagonal meets it.

Steering transient response test (Steering wheel angle step input). The steering wheel angle are respectively $28.5^{\circ}, 37.5^{\circ}, 47.25^{\circ}, 56.25^{\circ}$ and $66^{\circ}$ with the lateral acceleration of $1.0 \mathrm{~m} / \mathrm{s} 2,1.5 \mathrm{~m} / \mathrm{s} 2$, $2.0 \mathrm{~m} / \mathrm{s} 2,2.5 \mathrm{~m} / \mathrm{s} 2,3.0 \mathrm{~m} / \mathrm{s} 2$. Set the simulation speed $80 \mathrm{~km} / \mathrm{h}$ and steering wheel $28.5^{\circ}$ and $66^{\circ}$ respectively. As shown in Fig. 7 and Fig. 8, test field should not be less than $140 \mathrm{~m} * 25 \mathrm{~m}$. Test is safe with the lateral acceleration less than $3.0 \mathrm{~m} / \mathrm{s} 2$. 


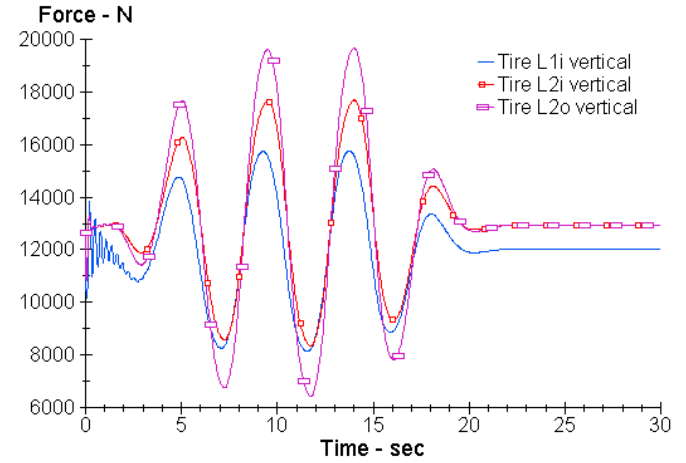

Fig. 5 Vertical forces of left tires of pylon course slalom test

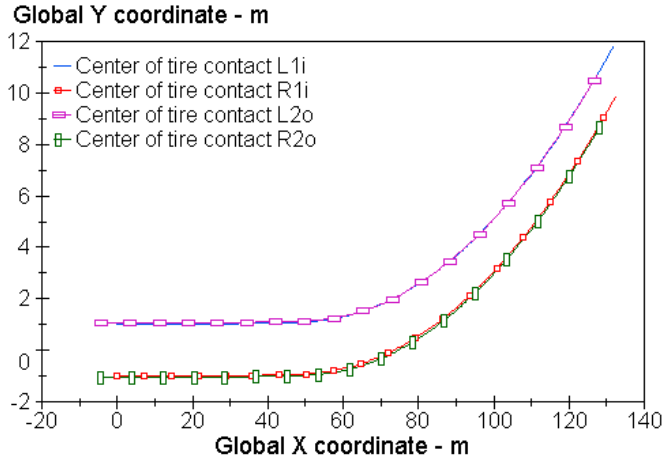

Fig.7 Center of tire contact of steering wheel angle step input with $28.5^{\circ}$

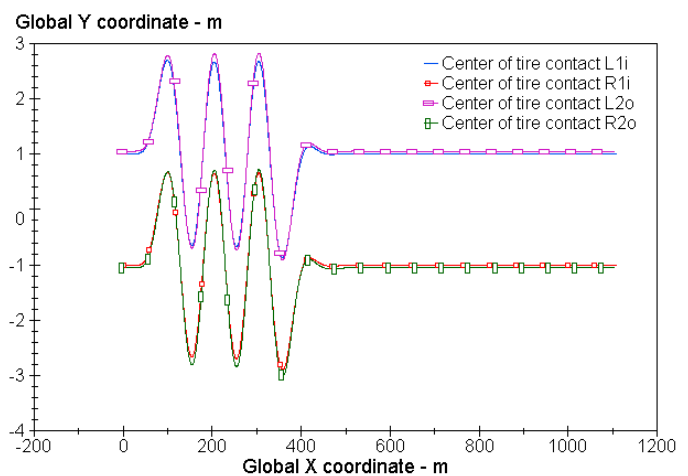

Fig.6 Center of tire contact of pylon course slalom test

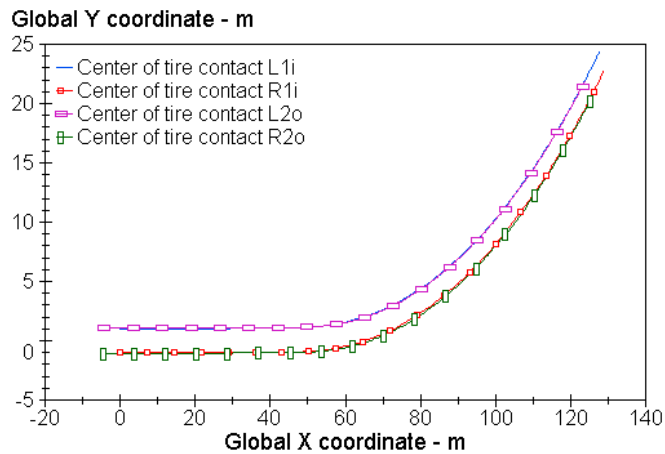

Fig. 8 Center of tire contact of steering wheel angle step input with $66^{\circ}$

Steering transient response test (steering wheel angle pulse input). Test speed is $80 \mathrm{~km} / \mathrm{h}$, and steering wheel angle is $300^{\circ}$, and the period is $0.4 \mathrm{~s}$. The maximum lateral acceleration reaches $4 \mathrm{~m} / \mathrm{s} 2$, which meets the standard requirements. Turn the steering wheel right and left three times respectively, and the time interval of each input must not be less than 5s, as shown in Fig. 9. As shown in Fig. 10, the two consecutive trials needs at least $500 \mathrm{~m}^{*} 45 \mathrm{~m}$, so pulse test can only be carried out 1 cycle at a time.

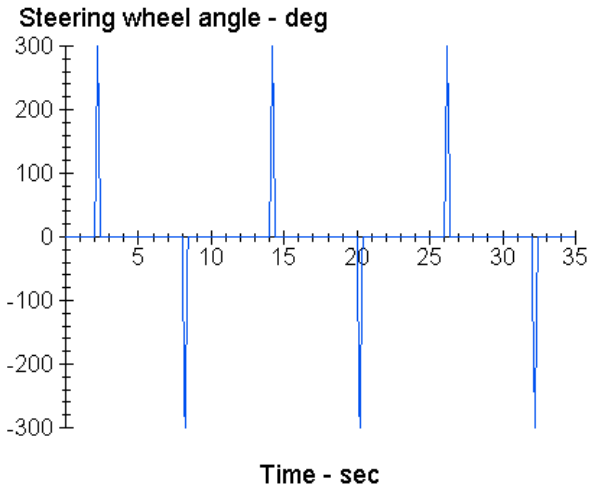

Fig.9 Steering wheel angle of pulse input

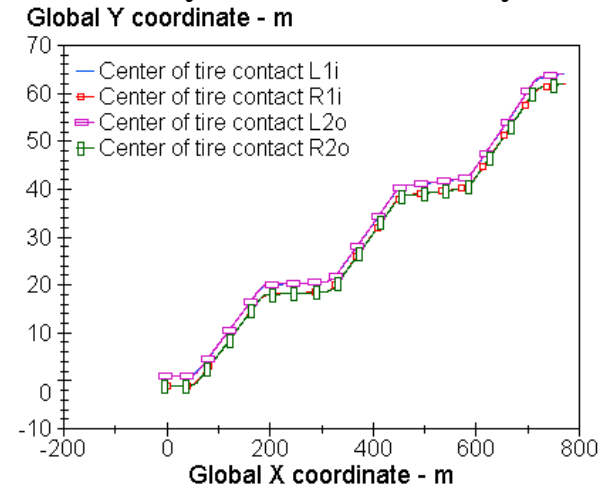

Fig.10 Center of tire contact of of pulse input

Returnability test with low speed. The radius is $15 \mathrm{~m}$; the lateral acceleration reaches $4 \mathrm{~m} / \mathrm{s} 2$; the vehicle speed is $27 \mathrm{~km} / \mathrm{h}$; the steering wheel angle is $481.3 \square$. Record vehicle movement process of release $4 \mathrm{~s}$ at least. Fig. 11 shows that the field can only be $50 \mathrm{~m} * 35 \mathrm{~m}$. Vehicle is rollover at the speed of $40 \mathrm{~km} / \mathrm{h}$ in this test.

Returnability test with high speed. The speed is set to 80 . According to the lateral acceleration of $2.0 \mathrm{~m} / \mathrm{s} 2$, the steering wheel angle is $47.25 \square$. Fig. 12 shows that the area is at least $120 \mathrm{~m} * 20 \mathrm{~m}$. 


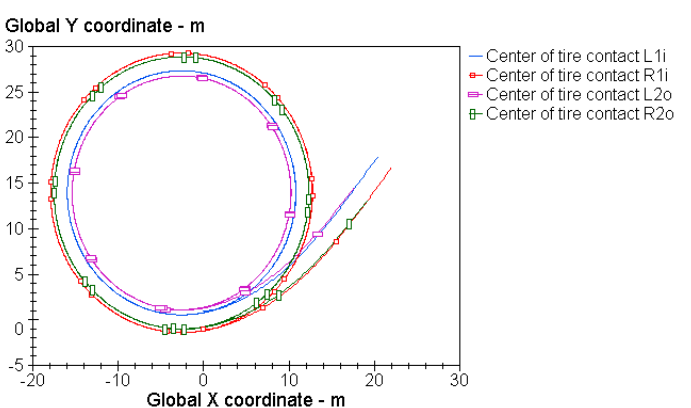

Fig.11 Center of tire contact of returnability test with low speed

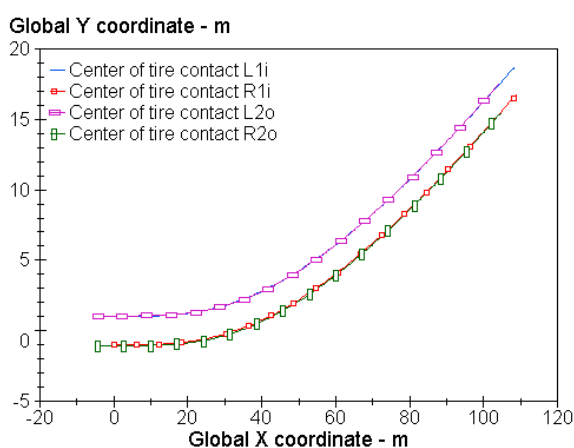

Fig. 12 Center of tire contact of returnability test with high speed

Steering efforts test. The velocity is $10 \mathrm{~km} / \mathrm{h}$. This test is relatively safe with low speed. As shown in Fig. 13, the test space is about $60 \mathrm{~m} * 25 \mathrm{~m}$, which is related with the vehicle parameters such as wheelbase and angle of lock.

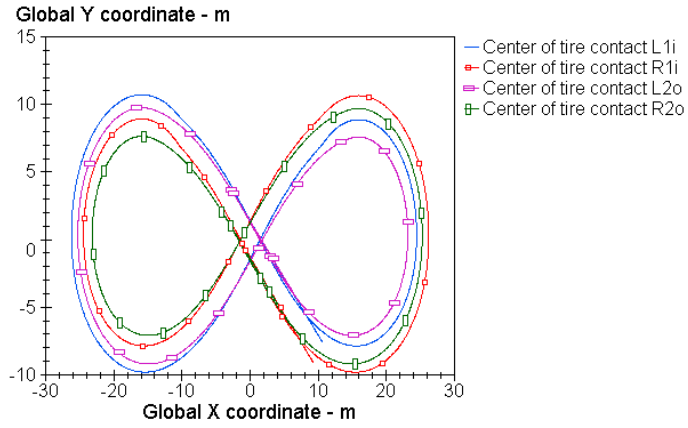

Fig.13 Center of tire contact of steering efforts test

Steering wheel center position test. The test speed is $80 \mathrm{~km} / \mathrm{h}$ and the lateral acceleration peak is not more than $4 \mathrm{~m} / \mathrm{s} 2$. The test should be at least 40s with manual input, to ensure that at least 8 input cycles. Data records should be above 1s after the end of the experiment. Therefore, at least $41 \mathrm{~s}$ of the test should be carried out. Fig. 14 shows that the space is at least $865 \mathrm{~m} * 67 \mathrm{~m}$. The built square cannot meet the requirements, and a series of short data are combined for testing analysis with at least 20 cycles of data. The test is carried out at least $20 \mathrm{~s}$ with robot, in order to ensure that at least 4 cycles is obtained, plus 1s after the end of the test, so the tests were carried 21s. Fig. 15 shows that the space is at least $865 \mathrm{~m} * 67 \mathrm{~m}$ with robot, only the diagonal of built square meets the requirement.

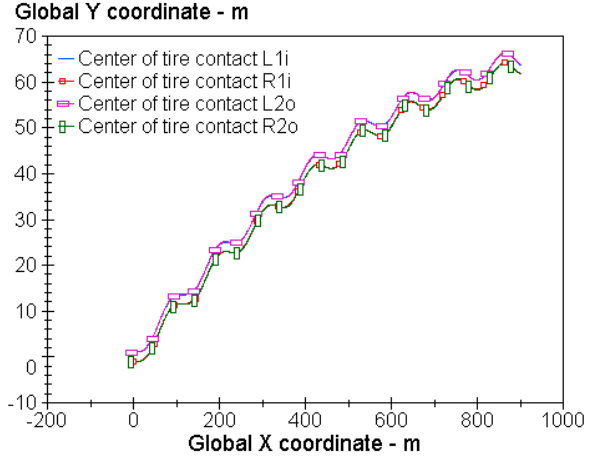

Fig.14 Center of tire contact of steering wheel center position test with manpower

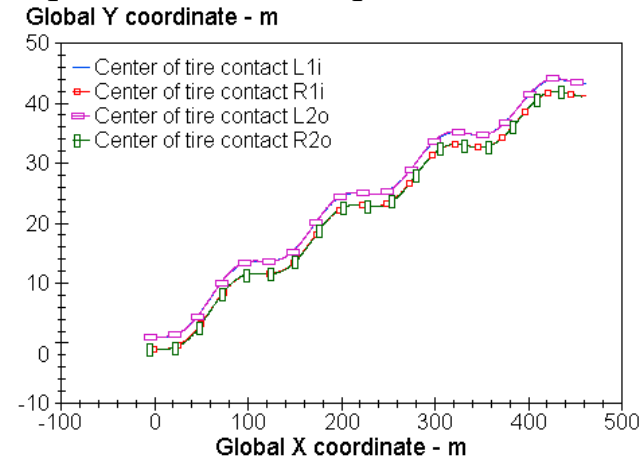

Fig.15 Center of tire contact of steering wheel center position test with robot

\section{Conclusions}

In order to avoid vehicle rollover, the lateral acceleration of vehicle should be less than $0.6 \mathrm{~g}$ controlling the steering angle and frequency and vehicle velocity. The controllability and stability test of GB/T6323-2014 can be completed in the built square, but some tests can only be done in the diagonal region, so the square utilization is not high. 


\section{Acknowledgements}

This work was financially supported by central level public Interest research institute of basic scientific research business expenses special funds (2013-9027).

\section{References}

[1] SAE J266-1996, Steady - state directional control test procedures for passenger cars and light trucks[S].

[2] JASO C705-2004, Road vehicles - Static steering efforts test procedure[S] .

[3] JASO Z 110-1991, Transient response test procedures for passenger cars [S] .

[4] JASO C704-2004, Road vehicles-Steering efforts (in cornering) test procedure [S] .

[5] JASO C707-2004, Passenger car - Light trailer combinations - Lane change test procedure[S]

[6] JASO C706-1987, Pylon Course Slalom Test Procedure[S] .

[7] ISO 4138-2004, Passenger cars - Steady-state circular driving behaviour - Open-loop test methods $[\mathrm{S}]$.

[8] ISO 14792-2003, Road vehicles - Heavy commercial vehicles and buses - Steady-state circular tests[S] .

[9] ISO 7401-2011, Road vehicles - Lateral transient response test methods - Open - loop test methods[S] .

[10]ISO 17288-1-2002, Passenger cars-Free-steer behavior - Part1 : Steering - release open - loop test method[S] .

[11]ISO 12021-2010 , Road vehicles - Sensitivity to lateral wind-Open-loop test method using wind generator input $[\mathrm{S}]$.

[12] ISO 14794-2003, Heavy commercial vehicles and buses - Braking in a turn - Open-loop test methods[S] .

[13]ISO 14791-2000, Road vehicles - Heavy commercial vehicle combinations and articulated buses - Lateral stability test methods[S] .

[14]ISO 3888-1:1999, Passenger cars - Test track for a severe lane-change manoeuvre - Part 1: Double lane-change[S] .

[15]ISO 3888-2:2011, Passenger cars - Test track for a severe lane-change manoeuvre - Part 2: Obstacle avoidance $[\mathrm{S}]$.

[16]GB/T 6323-2014, Controllability and stability test procedure for automobile [S] . 
[17]QC/T 480-1999, Criterion thresholds and evaluation of controllability and stability for automobiles[S] .

[18]GB 18565-2001, Multiple performance requirement and detecting methods for commercial vehicles $[\mathrm{S}]$.

[19]GB/T 26778-2011, Combination of vehicle performance requirements and test method[S]. 